\title{
EL ARTE ANTI-ARTÍSTICO Y LA NUEVA POESÍA: POEMAS, ARTÍCULOS Y MANIFIESTOS DE LUIS BUÑUEL Y SALVADOR DALÍ ANTERIORES A 1930
}

\author{
María Clementa Millán Jiménez \\ UNED \\ mclemmillan@flog.uned.es
}

\section{RESUMEN}

En este trabajo se muestran algunas de las conexiones entre la pintura, el cine y la literatura existentes en la vanguardia española de finales de los años veinte. En especial, entre las creaciones de Dalí, Buñuel y García Lorca, amigos desde su estancia en la Residencia de Estudiantes de Madrid. No solo a través de sus producciones más características, en el caso de los dos primeros, sino también a través de sus poemas, artículos y manifiestos, fundamentalmente a través de los artículos de Salvador Dalí. Las novedosas teorías de Dalí y Buñuel sobre el arte anti-artístico, expresadas en estos escritos podrían explicar algunas de las características de la nueva poesía de 1929, cercana al surrealismo, en especial varias de las que aparecen en la obra de Federico García Lorca, Poeta en Nueva York.

Palabras Clave: Salvador Dalí, Luis Buñuel, Federico García Lorca, Arte antiartístico, Surrealismo francés.

\section{Abstract}

With this work we want to show some of the existing connections among painting, cinema and literatura in the Spanish vanguard at the end of the nineteen twenties; in special around the group of friends, Dalí, Buñuel and García Lorca, living in the 
Residencia de Estudiantes in Madrid. For this, we will analyze, not only their most well-known creations, in the case of the first two, but also their writings, poems, articles and manifestos, in special those of Salvador Dalí. Buñuel and Dalí's new theories about the anti-artistic art, shown in these writings, help to explain many of 1929 new poetry's characteristics, close to surrealism, in special in Federico García Lorca's work Poeta en Nueva York.

Keywords: Salvador Dalí, Luis Buñuel, Federico García Lorca, Anti-artístic Art, French surrealism.

Una de las características más sobresalientes de la vanguardia española del primer tercio del siglo XX es la estrecha conexión existente entre las diferentes artes, fundamentalmente entre la pintura, la literatura y el cine; en especial, cuando esta relación se ve favorecida, entre otros muchos factores (como la influencia del cine mudo en la literatura del momento) por la estrecha amistad existente durante unos años entre Buñuel, Dalí y García Lorca ${ }^{1}$.

La repercusión de esta amistad, que arranca de su estancia común en la Residencia de Estudiantes de Madrid $^{2}$, va a propiciar el asentamiento de una nueva tendencia artística, que sustituirá a las vanguardias precedentes, como el Cubismo en pintura, y el Ultraísmo y el Creacionismo en literatura. Esta nueva vanguardia, denominada por Dalí y Buñuel arte anti-artístico, parece estar provocada en sus manifestaciones literarias, además de por la presencia de Pablo Neruda en Madrid en esos años, y la anterior influencia de Juan Ramón Jiménez ${ }^{3}$, por la repercusión, entre otras causas, de las teorías surrealistas francesas; fundamentalmente, a raíz de la publicación, en 1924, del Premier manifeste surréaliste de André Bretón, y su traducción casi inmediata al castellano, así como por la conferencia dada en abril de 1925 en la Residencia de Estudiantes por Louis Aragon, uno de los principales poetas surrealistas franceses.

Luis Buñuel, residente en París desde principios de 1925 hasta el otoño de 1928, conoció directamente las teorías francesas, al igual que otros vanguardistas del momento, como José María Hinojosa ${ }^{4}$ y Juan Larrea, residentes también en París en esos años veinte. Su poema en prosa de 1924, Palacio de hielo (publicado en la revista Horizonte de Madrid) muestra la absorción, a pesar de lo temprano de su fecha, del cambio de rumbo estético que se estaba produciendo en el arte. Muchas de las imágenes crueles aquí utilizadas anticipan las que aparecerían en la película realizada años más tarde con Salvador Dalí, Un chien andalou, que será considerada por André Breton (después de su estreno en París) símbolo del cine auténticamente surrealista. Dice Buñuel en Palacio de hielo:

\footnotetext{
1 Sobre la relación de estos tres autores, Agustín Sánchez Vidal, Buñuel, Lorca, Dalí: El enigma sin fin, Barcelona, Planeta, Premio Espejo de España, 1988.

2 Buñuel es el primero que llega a la Residencia en 1917, seguido por Lorca en noviembre de 1919, y por Dalí en septiembre de 1922.

${ }^{3}$ Especialmente, su obra Diario de un poeta recién casado, publicado en 1917. Sobre este libro, Miguel Ángel Pérez Priego, «El género literario de Diario de un poeta recién casado», Juan Ramón Jiménez en su centenario, Cáceres, 1981, p.114 y ss.

${ }^{4}$ Sobre este autor, Julio Neira, Viajero de soledades (Estudios sobre José María Hinojosa), Sevilla, Fundación Genesian, 1999.
} 
Cerca de la ventana pende un ahorcado que se balancea sobre el abismo cercano de la eternidad aullando despacio. SOY YO. Es mi esqueleto del que ya no quedan sino los ojos. Tan pronto sonríen, tan pronto bizquean, tan pronto SE VAN A COMER UNA MIGA DE PAN EN EL INTERIOR DEL CEREBRO. La ventana se abre y aparece una dama que se da polisoir en las uñas, cuando las considera suficientemente afiladas me saca los ojos y los arroja a la calle. Quedan mis órbitas solas, sin mirada, sin deseos, sin mar, sin polluelos, sin nada ${ }^{5}$.

La inconexión lógica de este texto y, sobre todo, la expresión de un mundo negativo, construido a base de imágenes al borde de lo macabro (procedentes del inframundo literario de los surrealistas franceses, extraído de Lautréamont y Sade, y también de Freud ${ }^{6}$ ) contrastan con la mayor parte de la poesía ultraísta y creacionista que se hacía en España en esos años. Esta inconexión aparecerá también en otros poemas de Buñuel, escritos hacia 1927, como los titulados Combate entre hormigas y hostias consagradas, y El arco íris y la cataplasma, reproducido a continuación.

¿Cuántos maristas caben en una pasarela?

¿Cuatro o cinco?

¿Cuántas corcheas tiene un tenorio?

1.230 .424

Estas preguntas son fáciles.

¿Una tecla es un piojo?

¿Me constiparé en los muslos de mi amante?

¿Excomulgará el Papa a las embarazadas?

¿Sabe cantar un policía?

¿Los hipopótamos son fáciles?

Dentro de unos instantes vendrán por la calle dos salivas en la mano conduciendo un colegio de niños sordomudos. ¿Sería descortés si yo les vomitara un piano desde mi balcón? ${ }^{7}$

Este poema interesa destacarlo, más que por su incierta calidad poética, por la libertad y la actitud de rebeldía contra lo establecido que conlleva, al presentar un espíritu semejante al de algunos de los escritos de protesta surrealistas; como los publicados en la revista La Révolution Surréaliste sobre L'Affaire Aragon, donde el grupo defiende el poema de Louis Aragon, Front Rouge, frente a los ataques de la crítica burguesa. Asimismo, la burla de Buñuel de la Iglesia como institución, «¿Cuantos maristas caben en

5 Aranda, J. F. Luis Buñuel, biografía crítica, Barcelona, Lumen, 1969. p. 285.

${ }^{6}$ Los cantos de Maldoror de Lautréamont (conocidos ya por los Modernistas) son traducidos en Madrid en 1922 por la editorial Biblioteca Nueva, que también traduciría en 1924, La interpretación de los sueños de Freud, cuyas obras «eran devoradas» por Buñuel y Dalí. (Ian Gibson, Lorca-Dalí. El amor que no pudo ser, Barcelona Plaza y Janés, 1999, p.114. Premio Así fue, 1999.

7 Poema reproducido por Aranda, op. cit. pp. 286, perteneciente al libro inédito de Buñuel de 1927 El perro andaluz. Título que pasó posteriormente a su película con Dalí. Buñuel también escribiría un guión de cine titulado Ilegible, hijo de flauta, que nunca llegó a materializarse en la pantalla. Sobre la producción literaria de Buñuel, Sánchez Vidal, Agustín (Edición) Luis Buñuel. Obra literaria, Zaragoza, Ediciones de El Heraldo de Aragón, 1982. 
una pasarela?» (imagen similar a la utilizada en su película Un chien andalou) participa de lo expresado por el grupo francés en su escrito Adresse au Pape, publicado en el N. 3 de La Révolution Surréaliste:

Nous n'avons que faire de tes canons, index, péché, confessionnal, pétraille, nous pensons à une autre guerre, guerre à toi, Pape, chien...Du haut en bas de ta mascarade romaine ce qui triomphe c'est la haine des vérités immédiates de l'âme...Il n'y a pas Dieu, de Bible ou d'Évangile, il n'y a pas de mots qui arrêtent l'esprit.

En 1929 Luis Buñuel publica otros poemas en varias revistas de vanguardia, como «Pájaro de angustia» (Hélix) y «Redentora»y «Bacanal»(La Gaceta Literaria). En el primero de ellos, recogido más abajo, utiliza la imagen de la «mano despellejada», semejante a las de las manos cortadas, empleadas frecuentemente por los surrealistas franceses en muchas de sus manifestaciones literarias, pictóricas y cinematográficas, tales como las representadas en el cuadro de 1927 de René Magritte, La travesía difícil, y semejantes a las utilizadas por García Lorca en varios de sus dibujos de esos años. Dice Buñuel en este poema:

Tu cuerpo se ajustaba al mío como una mano se ajusta a lo que quiere ocultar despellejada me mostraban tus músculos de madera y los ramilletes de lujuria que podían hacerse con tus venas ${ }^{8}$

En otro de estos poemas, «Bacanal», Luis Buñuel emplea con mayor intensidad la denominada escritura automática, defendida por los surrealistas franceses, y realizada sin la intervención de la conciencia, mediante la yuxtaposición de elementos diversos en contextos no habituales:

Carnero de 125 pesetas,

rizado abundoso, manual como el vientre

de la mujer de 150 pesetas:

los panes que come el pobre

pueden amasarse de ese vientre

y cocerse con fuego de pulgares.

Cuando cruzamos los pulgares para formar un aspa

se renueva el martirio de San Bartolomé,

que, como se supo después, era un diablo

o un fauno

que se reía de la cruz.

Al morir se lo comieron unas hormigas de oro,

de carne de mora,

de culo de bayadera.

San Bartolomé y el fauno danzaban

cuando las piedras salían disparadas de la tierra

como besos tirados con la punta de los dedos.

${ }^{8}$ Hélix, n. 4 Mayo, 1929, p. 5. 
De la tumba de San Bartolomé sale una espiga de bronce por cada beso que pudo y no quiso robar ${ }^{9}$

El tono poético empleado por Luis Buñuel en sus creaciones literarias, de las que solo hemos recogido una muestra, coincide en muchos aspectos con el que hacia 1929 aparecerá en los poetas del 27, como Aleixandre, Alberti y García Lorca (en menor grado Cernuda), así como en otros poetas de la vanguardia, como el citado José María Hinojosa, en su obra La flor de Californía, de 1927, o Juan Larrea, en sus prosas poéticas, tituladas Diente por diente. Casi todos ellos utilizarán una imaginería común, como las hormigas, las manos cortadas y los ojos dañados, entre otras muchas, tan frecuentes en gran parte de las manifestaciones surrealistas, tanto pictóricas, como cinematográficas; entre ellas la conocida e impactante imagen de una cuchilla de afeitar cortando una pupila en la película de Buñuel y Dalí, Un chien andalou.

Estos poemas de Luis Buñuel no presentan una calidad comparable a la de su excelente obra cinematográfica. Sin embargo, tienen un gran valor por significar el anticipo de un clima poético, que tendrá su máxima expresión en los poetas del 27 antes mencionados, y en obras escritas alrededor de 1929, como Pasión de la tierra de Aleixandre, Sermones y moradas de Alberti, Un río, un amor de Cernuda, y Poeta en Nueva York de García Lorca. El arte anti-artístico de Buñuel en estos poemas, junto a las influencias de Dalí y del resto de poetas citados, entre otros del momento, fueron el sustrato necesario para la explosión de la nueva poesía de 1929.

SALVADOR DALÍ también escribió poemas y prosas poéticas con anterioridad a 1930, con un lenguaje muy semejante al utilizado por Buñuel. Entre estas creaciones, destacan las publicadas en La Gaceta Literaria y, especialmente, en la revista de Sitges, L'Amic de les Arts, perteneciente al grupo vanguardista catalán capitaneado por el propio Dalí y del que formaban parte Sebastià Gasch y Lluis Montanyà. Su primer número saldría en 1927 y allí publicaría Dalí sus primeras prosas poéticas, como Sant Sebastià (dedicada a Federico) y otras dos prosas aparecidas en un número posterior de L'Amic: Nadal en Brusel.les (conte antic) y La meva amiga y la platja ${ }^{10}$ (encabezada esta prosa por el epígrafe La mel és més dolça que la sang). Este epígrafe lo utilizará después Dalí como título de uno de los cuadros de su época lorquiana ${ }^{11}$, compuesta fundamentalmente por dos obras: La miel es más dulce que la sangre (considerado por Dalí uno de sus cuadros más importantes) y Cenicitas (1928), ya que en ambos cuadros aparece entre otros muchos objetos la cabeza de Federico. En esta misma revista catalana García Lorca publicaría, en 1928, sus primeras prosas poéticas, Nadadora sumergida y Suicidio en Alejandría, como muestra de su adhesión a los postulados del Dalí de ese momento (con quien había compartido todo el verano de 1927) sirviendo a la vez, estas creaciones, de puente estético entre el mundo poético del Romancero gitano (publicado en 1928) y el que aparece en sus creaciones neoyorquinas de 1929-30.

\footnotetext{
9 La Gaceta Literaria, N. 50 enero, 1929.

${ }^{10}$ L'Amic de les Arts, n.20, noviembre 1927, p.104. Traducción de Cristina Andreu y Joanna Ferragut, a las que agradezco su colaboración. También agradezco a Rafael Cano el haberme facilitado estos textos.

11 Denominación acuñada por Rafael Santos Torroella, El primer Dalí.1918-1929, Publicaciones de la Residencia de Estudiantes, 2005.
} 
En la citada prosa de Salvador Dalí, Mi amiga y la playa, de 1927, aparece de nuevo la imagen del ojo seccionado, utilizada también por Buñuel en varias de sus creaciones literarias, y que tanta conmoción produjo en Un chien andalou. «A mi amiga le gustan las morbideces adormecidas de los lavabos y las dulzuras de los finísimos cortes de bisturí sobre la curvada pupila», dice Dalí. Esta imagen, de carácter casi sádico, participa del señalado inframundo surrealista francés, al que Louis Aragon parecía referirse al afirmar «En todo lo que es bajo, hay algo de maravilloso que me dispone al placer». Dalí dice en Mi amiga y la playa:

Contrayendo los nervios y apretando nuestras pupilas con las puntas de los dedos, sentiremos la alegría gutural de las venas al romperse, y los mil sueños de nuestra sangre al saltar a presión por cada nueva herida.

En otra de las prosas citadas, Navidad en Bruselas, Dalí, utiliza una imagen parecida: «Un ojo bien abierto con un pelo atravesado», de gran semejanza, a su vez, con el cuadro de Miró, Cabeza de un hombre fumando. Estas imágenes del cuerpo humano mutilado están tomadas de Freud y del surrealismo francés (como se puede ver, entre otras muchas obras, en la de André Breton, Poisson solubre: «un torse de femme adorablement polí bien qu'il fût dépourvu de tête et de membres»), y también aparecen en muchos cuadros de la época, como Estampa de Maruja Mallo. Dalí las utilizará en la prosa anteriormente mencionada de Mi amiga y la playa: «Mi amiga está acostada con las extremidades tiernamente seccionadas, llena de moscas y de pequeñas hélices de aluminio que acuden a su desnudo semi-vegetal».

El tono poético de estas creaciones literarias de Dalí, contagiadas de surrealismo, se corresponde con el cambio de rumbo iniciado en su PINTURA hacia 1927, por el que abandona las creaciones cubistas de obras anteriores para emprender un arte anti-artísti$c o$, cercano al surrealismo. Sus primeras obras pictóricas presentaban un carácter realista, o estaban ligadas a la pintura cubista, al igual que las de su primera exposición, realizada en Madrid de forma colectiva en 1925, y que fue reseñada por José Moreno Villa en la Revista de Occidente. En ellas se adivinaban algunos rasgos de su nueva estética, como señala Moreno Villa, quien, sin embargo, llama a Dalí «geómetra» por sus cuadros «cubistas», a la vez que resalta sus otras creaciones más cercanas a lo «neoclásico», como su conocido retrato de Luis Buñuel. Dice Moreno Villa:

Son sus obras las que más protestas han suscitado en el visitante inseguro. Y todo por los objetos que utiliza para sus construcciones plásticas. Este visitante dista mucho todavía de comprender y admitir que entre la figura humana y un sifón no hay diferencias para un pintor como Dalí. La nitidez y hasta la dureza de los perfiles es otra de las características de su obra.

En noviembre de 1925, Dalí realiza su primera exposición individual en las Galerías Dalmau de Barcelona, donde, entre otras obras de corte cubista, presenta su famoso cuadro de su hermana Anna María, Muchacha en la ventana (1925). Su segunda exposición individual tendría lugar, asimismo, en las Galerías Dalmau, entre el 31 de diciembre de 1926 y el 14 de enero de 1927, con cuadros también de corte cubista; aunque en esta exposición se podían entrever ya más claramente algunas de las características más representativas de la pintura daliniana posterior, como se desprende de las reseñas realizadas por Sebastiá Gasch y M. A. Cassanyes en L'Amic de les Arts. 
Sebastià Gasch destaca ${ }^{12}$, como propiedad esencial en la pintura de Dalí de ese momento, «la composición», «las intenciones constructivas del joven artista y su sumisión absoluta a la composición». Sin embargo, aún en las telas cubistas expuestas, «el dogma ha sido considerablemente suavizado por la voluntad del pintor de otorgar una mayor expansión al instinto», a la vez que la sensibilidad (y «al hablar de sensibilidad nos referimos a fuerza, intensidad, virilidad») «está por encima de la fría inteligencia». Entre las diferentes obras, Gasch cita Figuras tendidas en la arena, «tela de una expresión toda profundidad que parece salida de las manos de algún cuatrocentista torturado». En ella, aparecen varios cuerpos de mujeres sin cabeza, tendidos en la playa, característicos de lo que será la nueva tendencia estética del pintor. Sin embargo, según Gash, las creaciones dalinianas de esos años no pueden compararse por su incipiente calidad con las más consolidadas de Picasso o Miró.

Vivir una vida interior potentísima y estar lleno de un instinto formidable, cualidades que actualmente no posee ninguno, fuera de Picasso y Joan Miró. Cualidades con que Dios no ha favorecido ciertamente a Salvador Dalí.

M. A. Cassanyes observa, sin embargo, en esta misma exposición de Dalí, la importancia del espacio (que casi coincide con el título de su artículo ${ }^{13}$ ) y divide las obras expuestas en objetivas y cubistas. Las objetivas son «las más sobresalientes de la exposición. Este hecho es debido a que en ellas una atención amorosa y un análisis a fondo las ha envuelto en un halo vital, en cierta manera extraño al espíritu de Dalí, que es, habitualmente, un espíritu claramente racionalista con base sensualista, donde domina el sentido formalista». Dentro de este grupo, Cassanyes cita la obra Marina con una mujer en el baño, que merece destacarse por el «agudo sentimiento espacial que revela».

La concepción del espacio en Dalí, según Cassanyes, es distinta a la «impresionista», pues en esta última se «simula el espacio», en el que se «disuelven los contornos (...) de acuerdo con un fin superficialmente ilusionista». Sin embargo, la visión de Dalí que opera en esta Marina es, de cara al impresionismo, «un concepto puro del espacio, según la teoría Kantiana», expresado como «fundamento de la posibilidad de representación de los objetos exteriores». También en este cuadro (y en oposición a la «pasiva visión impresionista», por la cual «la distancia o el espacio no es otra cosa que la gradual invisibilización de los objetos dentro del campo visual») el espacio se afirma en Dalí rotundamente en «activa intuición»: «Mirar el Océano es igual que recorrerlo», dice Cassanyes:

En la Marina de Dalí el espacio se representa como tal, desnudo, en toda su sencilla grandiosidad; y las cosas en él contenidas no sirven más que para marcar el ritmo (... ) Rara aptitud de Dalí para vivir y sentir el espacio como tal, con toda su potencia originaria; la cual, captada no por medio de la observación y del análisis, sino por la pura intuición, nos prueba con incontrastable evidencia la agudeza de su concepción del espacio

Las obras cubistas de Dalí en esta exposición, según Cassanyes, «son fallidas, provienen de la imitación, a veces demasiado directa, de las últimas creaciones de Picasso» (coincidiendo su opinión con la de Sebastià Gasch, citada con anterioridad). Sin embar-

\footnotetext{
12 «Salvador Dalí», L’Amic de les Arts, $n .11$, febrero 1927, pp.16-17. Traducción de Andreu y Ferragut.

13 «El espacio en las pinturas de Salvador Dalí», L'Amic de les Arts, n.13, Abril 1927, pp.30-31. Traducción de Andreu y Ferragut.
} 
go, entre 1927 y 1929, la pintura de Dalí parece evolucionar visiblemente, como afirma Gasch en otro de sus artículos, «Obras recientes de Dalí», escrito en 1929. En este artículo $^{14}$ Gasch considera a Dalí de forma muy diferente a como lo hacía en 1927. Lo sitúa al lado de Joan Miró, al que había dedicado otro artículo ${ }^{15}$. Ya no habla de obras «cubistas» de Dalí, sino que afirma que «el cuadro-arquitectura va siendo lentamente sustituido por el cuadro-poema», y coloca al pintor al lado de Miró, calificando a ambos de «antipintores». La principal característica que Gasch destaca en estas obras de Dalí de 1929, considerado ya como uno de «los mejores pintores actuales», es la «dispersión de elementos que contrasta violentamente con la cohesión, propia de los cuadros de la precedente generación»:

Para el cubismo, una tela era (...) una compacta estructura completamente cerrada (...) El momento pictórico actual, en cambio, mucho más libre (...) se caracteriza por la dispersión de los elementos que el cubismo centralizaba. En las telas de algunos pintores actuales, los mejores, los elementos empleados no han sido situados uno al lado del otro, sólidamente unidos, estrechamente hermanados, sino que han sido colocados separadamente en el espacio de la tela. Evidentemente, hay un ritmo invisible que guía esa colocación. No se trata, empero de un ritmo concebido, sino de un ritmo intuitivo. Un equilibrio intuitivo, hijo, no de la voluntad, sino del instinto de orden que se halla en lo más profundo de nuestro ser.

(....)

La pintura está llamada a desaparecer; por haber devenido ya inapta para satisfacer las necesidades espirituales de nuestra época (...) Y enfrente de esas actividades pictóricas —actividades muertas - completamente al margen de las actividades vivas — actuales - hay el cinema (...) hay la fotografía (...) El artista en una época no tan lejana como parece, no pintará: exteriorizará su lirismo por otros medios más vivos, menos muertos, más actuales. El lirismo no morirá... Me decía Joan Miró que pensaba abandonar por cierto tiempo la pintura y entregarse a la confección de objetos, que serán tan intensamente poéticos, no lo dudo, como sus telas (...) Salvador Dalí, evadido completamente de la imitación de las apariencias de la realidad, crea ya libremente, sin trabas, y anota inconscientemente las chispas que brotan al chocar su alma con el alma de las cosas.

Estas apreciaciones de Sebastià Gasch sobre la pintura de Dalí coinciden con las palabras del pintor que, hacia 1927, había empezado a esbozar su nueva teoría anti-artística. La expresión teórica de este proceso estético se inicia en su importante prosa poética, Sant Sebastià , publicada en julio de 1927 en L'Amic de les Arts, y dedicada, como se ha dicho, a Federico (como colofón de su estancia catalana del verano de $1927^{16}$ ). García

${ }^{14}$ La Gaceta Literaria, n.51, febrero, 1929.

15 «La obra actual del pintor Joan Miró», L’Amic de les Arts, n. 5, agosto 1926, pp.15-16. (Traducción de Andreu y Ferragut ). Gasch define a Miró como el autor donde «el instinto y la inspiración tienen asignado un papel preponderante (...) Una obra tan pletórica de vida interior, tan rica de alma, tan empapada de subconsciente (...) Obra de imaginación pura, de pura sensibilidad». Estos elogios estaban dedicados a Miró con motivo del estreno en Londres de Romeo y Julieta por el ballet del músico inglés Constant Lambert. «Decorado por Miró con la colaboración del pintor alemán Max Ernst», ya que, desde varios años antes Joan Miró era considerado «pintor surrealista», exponiendo en París en 1925, presentado por Benjamín Péret.

${ }^{16}$ García Lorca había publicado con anterioridad, en junio de 1926, en la Revista de Occidente, el poema que tanto gustó al pintor, Oda a Salvador Dalí, escrita después de su primera visita catalana a Dalí en la Semana santa de 1925. Los años 1926-1927 significarían la cima de la relación Lorca-Dalí, mientras en 1928 se inicia su distanciamiento, provocado, entre otros factores, por la llegada de Luis Buñuel desde París. 
Lorca, que estaba suscrito a L'Amic, haría traducir la prosa de Dalí en su revista Gallo, según comenta con Anna María Dalí:

He recibido L'Amic de les Arts y he visto el prodigioso poema de tu hermano. Aquí en Granada lo hemos traducido y ha causado una impresión extraordinaria (...) Se trata sencillamente de una prosa nueva, llena de relaciones insospechables y sutilísimos puntos de vista.

En esta prosa poética, de gran significación en la trayectoria artística daliniana, Dalí combina sus reflexiones sobre su nueva teoría artística, opuesta al putrefacto arte anterior $^{17}$, con la creación literaria, al modo de sus otras prosas poéticas citadas:

Las flechas llevaban, todas, anotada su temperatura y una pequeña inscripción gravada en acero que decía: Invitación al coágulo de sangre (...) La aureola del mártir era como de cristal de roca y, en su whisky endurecido, florecía una áspera y sangrante estrella de mar (...). Uno de los aparatos llevaba este título Heliómetro para sordomudos (...un sencillo mecanismo indicador servía para medir la agonía del santo (...) En una varilla de cristal numerada se podía leer todavía: Medida de las distancias aparentes entre valores estéticos puros (...) Una flecha indicadora hacia abajo: Dirección Chirico hacia los límites de una metafísica (...) Sant Sebastià, lleno de simbolismos era un hecho en su única y sencilla presencia ${ }^{18}$.

Sin embargo, lo más significativo de esta prosa de Sant Sebastià tal vez sea la defensa de su peculiar y novedosa teoría de la Santa Objetivitat, que tanto le preocupaba en esos momentos de 1927-1928, y que debatiría intensamente con Federico durante su larga visita de $1927^{19}$ : «El olor de Sant Sebastià era un puro pretexto para una estética de la objetividad», dice Dalí en esta prosa. Esta objetividad, según Dalí, se lograba gracias a una luz purísima («dura luz de naipe», que diría García Lorca, refiriéndose a su propia poesía) donde las distintas realidades se percibían claramente, adquiriendo su máxima categoría plástica, aséptica y antiartística, que el ojo captaba súbitamente. El retrato de Man Ray de una magnolia, según Dalí, «es más eficiente para nuestra carne que las creaciones táctiles de los futuristas»:

La aséptica luz de la mañana me revelaba sus más pequeños detalles, con tal claridad y pureza, que no era posible mi turbación (...) todo esto estaba lejos de vaguedad, todo se veía, claramente con claridad de vidrio de multiplicar. Cuando paraba mis ojos encima de un detalle cualquiera, este detalle se engrandecía como en un gran plano cinematográfico y adquiría su máxima categoría plástica (...) Espectáculo aséptico, antiartístico, claridades concretas (...) oponiéndose al arte sublime, delicuescente, amargo, putrefacto (...). Un único ojo, súbitamente engrandecido y como un solo espectáculo, es todo un fondo y toda una superficie de océano, en la cual navegan todas las sugestiones poéticas y se estabilizan todas las posibilidades plásticas.

Estas consideraciones artísticas dalinianas coinciden con las expresadas en un artículo posterior, ya plenamente teórico, La fotográfia pura creaciò de l'esperit ${ }^{20}$, donde Dalí

17 Dalí consideraba a Juan Ramón Jiménez el «jefe de los putrefactos españoles», según señala a Pepín Bello en una carta de 1927 (Sánchez Vidal, op.,163.). Como «putrefactamente» realizado, denominaría Dalí el Romancero gitano de Lorca, en una importante carta a Federico de septiembre de ese año.

${ }^{18}$ L'Amic de les Arts, n.16, pp.52-53. Traducción de Andreu y Ferragut.

1919 «Infinitas conversaciones sobre la objetividad en el arte», Gibson, op. cit. p. 135.

${ }^{20}$ L'Amic de les Arts, n.18, sept.1927, pp. 90-91. Traducción de Andreu y Ferragut. 
defiende la objetividad conseguida a través de la fotografía, porque conserva intacto el objeto y lo trascribe con total exactitud, sin que el pensamiento o la moda artística intervenga en «el proceso inconsciente de la máquina» fotográfica: «Confiemos en las nuevas maneras de fantasía, nacidas de las sencillas transposiciones objetivas».

Un claro retrato de una orquídea, se une líricamente con el interior fotografiado de la boca de un tigre, donde el sol juega a las 1000 sombras con la arquitectura fisiológica de la laringe.

Como proclamación del nuevo arte, Dalí, Gasch y Montanyà publicarían en marzo de 1928, también en L'Amic de les Arts, su Full Groc. Manifest antiartistic català (que un mes después sería traducido en la revista granadina Gallo) donde asientan su nueva postura anti-artística, «viviendo a la vez de acuerdo con su época».

Sobre sus postulados estéticos insistirá de nuevo Salvador Dalí en su artículo de mayo de 1928, Nous limits de la pintura ${ }^{21}$, donde analiza la «producción plástica superrealista más reciente y aún el actual cubismo poético». Señala como principales características de la «pintura actual», la desaparición de la estabilidad geométrica, el dinamismo y, sobre todo, la recuperación de la verdadera realidad, diferente de la aceptada convencionalmente:

Antes de nada cabe señalar la desaparición casi total de la estabilidad geométrica (...). En la anulación del espíritu «octogonal» va implícita la aparición de un desequilibrio, de una dinámica. Esta dinámica, sin embargo, no tendrá nada que ver con la por excelencia ilusión sensorial del movimiento cinematográfico, el útimo refugio del impresionismo que intentaron los futuristas italianos. El dinamismo en cuestión está hecho de tal manera que por nuestros sentidos permanece como específicamente plástico y estático, mientras que psicológicamente actúa como una velocidad

\section{$(\ldots$.}

Por este sentido de la inspiración la realidad física recobra una apariencia normal en cuanto a su falta de aplicación conformista, que una lógica convencional ha dotado de atribuciones insuperablemente anti-reales, controladas solamente por el hábito, y de origen minuciosamente simbólico y estereotipado.

(...)

Si Miró reencontraba la naturaleza por inspiración, esta no es menos sensible en sus obras que en las de Max Ernst. Además, en el momento en que la inspiración, y aún el más puro subconsciente, han actuado para la revelación de nuestras verdades individuales, un mundo orgánico, lleno de atribuciones significativas ha invadido las figuraciones de los pintores. En estos momentos los hechos más emotivos y turbadores, adormecidos en lo más hondo de nuestros más íntimos horrores y alegrías, adquieren el máximo gusto de la luz. Con el cubismo la inteligencia habría servido no para hacer visible el espíritu, sino para sensualizarlo y reducirlo a un significado de cifra, de signo... de acuerdo con la arquitectura, pero nunca de acuerdo con las más violentas necesidades de carencia de cohesión.

(....)

En el momento en que las cosas se han aislado de lo convencional y han podido usar libremente de sus cualidades específicas e individualísimas (...) en el turbador proceso del

${ }^{21}$ L'Amic de les Arts, n. 24, abril, 1928, pp.185-86 y n.25, mayo, 1928, pp. 195-96. Traducción de Andreu y Ferragut. García Lorca responderá a estos postulados de Dalí con sus conferencias Imaginación, inspiración y evasión en la poesía, y Sketch de la nueva pintura, pronunciadas en el Ateneo de Granada el 11 y el 26 de octubre de 1928, respectivamente. 
instante (...) Este sentido orgánico y fisiológico que acaba de suplantar las más ineludibles vertebraciones arquitectónicas, la palabra realidad, sometida a un valor convencional en el Cubismo, vuelve a colocarse en primer plano (...) Ni una sola de las preocupaciones de los pintores antiguos mueve la mano de nuestros recientes artistas.

Dalí considera en este escrito la pintura como expresión de las nuevas maneras de la poesía, que «han nacido fuera de los límites que imponía el mecanismo de un verso; fuera de los límites de la literatura». Pero no se identifica totalmente con los planteamientos surrealistas, y opone su teoría de la objetividad a las manifestaciones subconscientes, donde el pensamiento lógico ha desaparecido; con afirmaciones semejantes a las realizadas en su artículo anterior, La fotografía, pura creació de l'esperit, donde afirmaba: «iFantasía fotográfica; más ágil y rápida en hallazgos que los turbios procesos subconscientes!». Así dice Dalí en Nous limits de la pintura:

Rehúso con todas mis fuerzas las tentativas que dentro del orden de la pintura, como de la escritura, podrían tener estrictamente la consecuencia de substraer el pensamiento de la vida, como también de colocar la vida bajo la tutela del pensamiento (...) iiAsesinato del arte, qué elogio más bello!! Los superrealistas son una gente que, honestamente, se dedican a esto mi pensamiento está bien lejos de identificarse con el suyo.

Estas ideas de Dalí sobre la objetividad y su importancia en la captación del objeto, tienen muchos puntos en común con las TEORÍAS de Luis Buñuel en esos años, con quien Dalí también había debatido su concepto del arte anti-artístico. En diciembre de 1927 (tres meses después de escribir su artículo La fotografía pura creació de l'esperit) le dedica a Buñuel su artículo Film-arte Film-antiartístico ${ }^{22}$. En él Dalí alaba al «filmador antiartístico» que «ignora el arte» y «capta seres y objetos insólitos», con ideas muy semejantes a las expresadas sobre la fotografía, pero ahora aplicadas a la creación cinematográfica. Posteriormente Luis Buñuel escribirá sus artículos, Del plano fotogénico y Découpage o segmentación cinematográfica, de grandes coincidencias con las ideas dalinianas. En el primero de ellos ${ }^{23}$, Buñuel afirma:

Un plano de Greta Garbo no es más interesante que el de un objeto cualquiera (...) «A l'ecran il n'y a pas de nature morte. Les objets ont des attitudes» ha dicho Jean Epstein, el primero en hablarnos de esa calidad psicoanalítica del objetivo (...) El drama termina por subordinarse también a las cosas. En un momento determinado una de ellas se alza con todo el interés y significado dramático. Entonces, el objetivo se dirige exclusivamente a ella, dejando todo lo demás, incluso el elemento humano como cosa mediata y farragosa

En el otro artículo citado ${ }^{24}$ Buñuel ratifica estas ideas («Un film sin intérpretes, a base de objetos naturales, de mediana técnica fotográfica, puede llegar a ser un buen film») y defiende las imágenes concretas, creadas por segmentación, que adquieren su verdadero sentido al estar encuadradas en un conjunto.

Segmentación. Creación. Escisión de una cosa para convertirse en otra. Lo que antes no era, hora es (...) Creación por segmentación (...) Una imagen aislada representa muy poco (...) El desfile silencioso de las imágenes, concretas, determinantes... Es un trabajo que no

\footnotetext{
22 «Traducido del catalán por el autor» para La Gaceta Literaria, n.24, diciembre, 1927.

${ }_{23}$ Publicado en La Gaceta Literaria, recogido por ARANDA, Luis Buñuel, op.cit.,p.319.

${ }^{24}$ La Gaceta Literaria, n.43, octubre, 1928.
} 
requiere otro trabajo que la pluma. Todo el film, hasta en sus mejores detalles quedará contenido en las cuartillas.

Estas ideas coincidentes de Luis Buñuel y Salvador Dalí sobre el nuevo tratamiento del objeto y de la imagen fueron aplicadas con éxito por estos dos autores (entonces amigos $^{25}$ ) en su película común, Un chien andalou, estrenada en París el 6 de junio de 1929, con el apoyo del grupo surrealista francés ${ }^{26}$. En esta película estaban plasmadas gran parte de las ideas, expuestas en sus artículos antes citados, sobre el nuevo arte, arte antiartístico, opuesto al compacto y «antiguo» arte cubista. Estas teorías consistirían, fundamentalmente, en la búsqueda de la emoción a través de la segmentación y dispersión de las imágenes, así como en la reproducción exacta de objetos (Santa objetivitat daliniana) sacados estos de sus contextos habituales, y enlazados por una concatenación dinámica y espacial (velocidad cinematográfica) ausente de todo hilo narrativo convencional.

Pero, a la vez, estas aportaciones estéticas de Dalí y Buñuel contribuirían también a la fijación de una nueva imaginería, y de una nueva forma de hacer poesía, definitorias del mencionado contexto literario de finales de los años 20. En él, el especial tratamiento del objeto, y la velocidad conseguida en sus textos para provocar emociones ajenas a planteamientos racionales, tenían una gran deuda con la pintura y el cine del momento. Pues Dalí y Buñuel, más que aceptar totalmente las consignas del Surrealismo francés, aportaron, cada uno a su modo, una manera complementaria a la surrealista de considerar la realidad, haciendo surreal lo real. Como dice Dalí en Sant Sebastià, «Todo se veía limpiamente» y «alcanzaba su más aguda categoría plástica», anticipando así su teoría de la Paranoia-crítica, principal aportación del pintor al surrealismo francés, por la que los instintos se reflejaban en materialidades perfectamente delimitadas. Por tanto, las teorías de Dalí y Buñuel, expuestas en sus artículos sobre el arte anti-artístico servirían, tal vez, para explicar mejor algunas de las características fundamentales de la nueva poesía de 1929, contagiada de surrealismo; en especial, la obra Poeta en Nueva York de su, en otra hora, común amigo, Federico García Lorca.

${ }^{25}$ La vuelta de París a Madrid de Luis Buñuel, en otoño de 1928, llevaría consigo su mayor acercamiento a Dalí (cada día más interesado en su traslado a París) y a la vez, el inicio de la separación Dalí - Lorca, ya que Buñuel intentaba «socavar el profundo afecto que siente Dalí por el poeta» (Gibson, p. 236). La llegada de Gala (entonces mujer del poeta surrealista francés Paul Èluard) a Cadaqués en agosto de 1929 marcaría una nueva etapa en la vida y la obra de Salvador Dalí, quien se casaría con Gala en 1930.

${ }^{26}$ El guión de Un chien andalou apareció publicado en el número 2 de La Revolution Surréaliste en 1929, y fue redactado en Figueres a finales de 1928, durante la visita de Buñuel a Dalí, momento en que «la correspondencia Lorca-Dalí quedó interrumpida» (Sánchez Vidal, op. cit., p.120 ). El último número de L'Amic (marzo 1929) estará dedicado casi exclusivamente a esta película, teniendo como portada el Manifest de Dalí, y como contraportada una entrevista a Buñuel. En la primavera de 1929 Dalí se trasladaría a París donde se estrenaría Un chien andalou. Posteriormente «se alistaría en las filas surrealistas», aportando su «teoría de la Paranoia-crítica (Gibson p.118) 